\title{
ANÁLISE PRINCIPIOLÓGICA DA MEDIAÇÃO COMUNITÁRIA NA PERSPECTIVA DO PLURALISMO JURÍDICO
}

\author{
Graziela Regina Munari Lothammer Carlos* \\ Sheila Rosane Vieira Rodrigues* \\ Antonio Carlos Wolkmer*
}

\begin{abstract}
RESUMO: O problema do presente artigo consiste na análise dos princípios norteadores da Mediação Comunitária na perspectiva do Pluralismo Jurídico. Assim, o objetivo geral é identificar as corretas interpretações de cada princípio, apontando os que são essenciais e que dão suporte a Mediação Comunitária, permitindo que a prática do método seja efetivo. $\mathrm{O}$ presente estudo compreende dois momentos: no primeiro, abordou-se a Mediação Comunitária e seus aspectos conceituais e, em um segundo momento, buscou-se realizar uma análise principiológica. $\mathrm{O}$ método de abordagem utilizado foi o dedutivo, com a técnica de pesquisa bibliográfica.
\end{abstract}

PALAVRAS-CHAVE: Conflitos; Acesso à Justiça; Mediação Comunitária; Princípios; Pluralismo Jurídico.

\section{PRINCIPLE ANALYSIS OF COMMUNITY MEDIATION FROM THE PERSPECTIVE OF LEGAL PLURALISM}

\begin{abstract}
The problem with this article is the analysis of the guiding principles of Community Mediation from the perspective of Legal Pluralism. Thus, the general objective is to identify the correct interpretations of each principle, pointing out those that are essential and that support Community Mediation, allowing the practice of the method to be effective. The present study comprises two moments: in the first, Community Mediation and its conceptual aspects were approached, and in a second moment, an attempt was made to
\end{abstract}

\footnotetext{
* Mestra em Direito pela Universidade do Extremo Sul Catarinense (UNESC). Pós-Graduada em Direito Civil e Direito Processual pela Universidade Luterana do Brasil (ULBRA). Graduada em Direito pela Universidade Luterana do Brasil (ULBRA). E-mail: grazyml@ rede.ulbra.br.

* Mestranda no Programa de Pós-Graduação em Direito da Universidade do Extremo Sul Catarinense (UNESC). Especialista em Direito Tributário pela Pontifícia Universidade Católica do Rio Grande do Sul (PUCRS). Graduada em Direito pela Universidade Luterana do Brasil (ULBRA). E-mail: sheilarvr@hotmail.com.

* Professor dos Programas de Pós-Graduação em Direito da UNILASALE-RS (Mestrado e Doutorado em Direito), e da UNESC-SC, onde coordena seu Mestrado em Direitos Humanos e o Grupo de Estudos NUPEC, e da UFSC (professor emérito e titular aposentado). Doutor em Direito. Membro do Instituto dos Advogados Brasileiros (RJ). É pesquisador nível 1-A do CNPq, e consultor ad hoc da CAPES. Membro da Sociedad Argentina de Sociologia Jurídica. Igualmente integrante de GT - "Crítica Jurídica y Conflictos Sociopolíticos", do Conselho Latino-americano de Ciências Sociais (CLACSO, Buenos Aires/México/Brasil). Membro da International Political Science Association (IPSA, Canada), and of the Research Committee on Sociology of Law (RCSL). Idem, do Instituto Internacional Derecho y Sociedad (Lima, Perú). Professor visitante de Cursos de Pós-graduação em várias universidades do Brasil e do exterior (Argentina, Peru, Colômbia, Chile, Equador, Venezuela, Costa Rica, México, Espanha e Itália).
} 
conduct a principled analysis. The method of approach used was the deductive one, with the technique of bibliographic research.

KEYWORDS: Conflicts; Access to justice; Community Mediation; Principles; Legal Pluralism.

\section{INTRODUÇÃO}

As inúmeras demandas e a morosidade do sistema judicial fazem com que a mediação de conflitos apresente-se como uma das melhores maneiras de solucionar casos conflituosos. Com o instrumento da Mediação, surgiu a oportunidade de as partes conflitantes encontrarem juntas a solução para o litígio, isso em situações que envolve diversos tipos de demandas.

Identifica-se a necessidade de buscar formas mais efetivas na aplicação da Mediação em comunidades, onde há a presença do Pluralismo Jurídico, considerando que a Mediação Comunitária é um transformador social com objetivo de transformar a cultura do litígio em uma cultura de paz, evitando assim o surgimento de novos conflitos.

A Mediação, em especial a Mediação Comunitária, surge como uma fomentadora do respeito, da participação e da de pacificação social. Há a conscientização, tanto dos mediadores quanto dos mediados, da responsabilidade social na prevenção e resolução dos conflitos, a fim de que prevaleça o bem-estar da coletividade.

O problema central desse estudo será identificar os princípios da Mediação Comunitária realizando-se um análise dos princípios da liberdade das partes, da decisão das partes, da não competitividade, da competência do mediador e da participação de terceiro imparcial, e da confidencialidade e informalidade do processo

Nesse contexto, o objetivo do presente artigo é realizar um estudo acerca da Mediação Comunitária, estudando seus aspectos conceituais e os princípios norteadores desse método consensual de solução de conflitos.

Pretende-se com o presente articulado responder o seguinte questionamento: como se dá a aplicação dos princípios da Mediação Comunitária, para que haja uma efetiva solução aos litígios?

Cabe mencionar, que não se tem a pretensão de afirmar quais as formas corretas de interpretação de cada princípio ou inviabilizar outras formas de interpretação. O intuito é trazer princípios essenciais que dão sustentação ao método da Mediação Comunitária e que 
fazem com que a prática deste tipo de Mediação seja efetiva, enquanto oportuniza as partes a buscar por si sós da pacificação social.

Para a realização desse estudo, utilizar-se-á como método de abordagem o dedutivo e de procedimento monográfico, com a técnica de pesquisa bibliográfica.

\section{A MEDIAÇÃO COMUNITÁRIA E SEUS ASPECTOS CONCEITUAIS}

A judicialização dos conflitos oriunda do entendimento de que somente o Estado têm capacidade de pôr fim a um litígio, visão essa que deve ser superada. Como bem aponta Antonio Carlos Wolkmer e Maria de Fátima S. Wolkmer (2021, p.130), “o projeto de normatividade centralizado no Estado e identificado com o mito da lei escrita constitui uma cultura monocultural e monista, que trará os traços caracterizadores de estatalidade, de unicidade, de positividade e de racionalidade"

Com a eclosão da litigiosidade, derivada pelo maior acesso à justiça, o Estado precisou buscar alternativas para resolução desses conflitos. No entanto, a litigância judicial ainda é tida como o principal meio de resolução de conflitos, consolidando o entendimento de que existe uma grande confusão do princípio constitucional do acesso à justiça com o acesso à atividade jurisdicional do Estado (ZANFERDINI, 2012, p.237-253).

Cabe mencionar que o acesso à justiça é um direito fundamental, previsto constitucionalmente como um instrumento de inclusão social, de efetivação de direitos e de concretização de uma vida digna, ainda que haja obstáculos de natureza econômica, processual e institucional para sua real efetivação (SILVA; THIBAU; MACHADO, 2015, p.389).

Para Mauro Cappelletti e Bryant Garth, o acesso à justiça é o mais básico dos direitos humanos, esclarecendo que este deve ser encarado como requisito fundamental de um sistema jurídico moderno e igualitário que pretenda garantir, e não apenas proclamador de direitos (CAPPELLETTI; GARTH, 1988, p.12).

Diante dessa crescente demanda, houve a necessidade de criar medidas alternativas para a solução dos conflitos. Assim, o Código de Processo Civil (Lei nº 13.105/2015) e a Lei da Mediação (Lei 13.140/2015), incluíram no ordenamento jurídico brasileiro instrumentos com a intenção de garantir a pacificação social, criando-se assim o instituto processual da Mediação, bem como as demais práticas de resolução consensual de conflitos 
(NASCIMENTO JÚNIOR, 2017, p.275).

Com isso, a edição do novo Código de Processo Civil de 2015, “consagrou-se definitivamente a promoção da solução consensual dos conflitos como princípio fundamental do ordenamento jurídico brasileiro" (PANTOJA; ALMEIDA, 2016, p.59).

Para Ivan Aparecido Ruiz (2015, p.286), a mediação não tem a escopo de afastar a utilização do processo judicial, porém deve ser incentivada e utilizada ao lado do processo tradicional, funcionando como verdadeiro filtro, sendo utilizada somente quando as partes por si sós não conseguem realizar a composição.

Posto isso, verifica-se que o objetivo da legislação não foi tão-somente criar instrumentos para aliviar o Judiciário, mas sim para que houvesse uma mudança de paradigma, fazendo com que a solução ultrapasse o processo judicial e se dê também na vida privada dos indivíduos envolvidos no litígio.

O autor Tauã Lima Verdan Rangel (2014, p.9), explica que:

(...) No sistema vigente, pautado na conflituosidade que caracteriza os procedimentos judiciais, os litigantes são obrigados, comumente, a apresentar motivos justificadores a existência do dissenso, buscando se colocar em situação de vítima e a parte ex-adversa como culpada pela ocorrência do conflito, utilizando, por vezes, de argumentos que são hipertrofiados e que não refletem, em razão do grau de comprometimento psicológico dos envolvidos, a realidade existente, aguçando, ainda mais, a beligerância entre os envolvidos.

Não se pode pensar na Mediação como uma forma de aliviar a sobrecarga do Judiciário, mas como uma forma de manutenção e restabelecimento dos laços entre os litigantes. Portanto, o objetivo da Mediação é o alcance do restabelecimento daquilo que ficou abalado na relação, resgatando-se a comunicação entre as partes, e com isso a reconstrução, fundada no respeito aos valores individuais e sociais (YAGODNIK; MARQUES, 2014, p.82).

Importante apontamento é feito por Esther Benayon Yagodnik e Giselle Picorelli Yacoub Marques (2014, p.82):

\footnotetext{
A mediação possui como principal diferencial o fato de que as partes em contenda participam da construção da solução através de uma prática dialógica e colaborativa sob a orientação do mediador que possui a função precípua de facilitador e canalizador do diálogo. Sendo a construção da solução produto das partes, há um maior grau de respeito a ela, na perspectiva da efetividade.
}

Daí a importância da Mediação para a construção e restabelecimento da relação entre 
as partes envolvidas no litígio. Nesse contexto, temos que:

A mediação realiza, através de uma pluralidade de formas, o fim que o Direito, na sua generalidade, parece negar ao singular: a possibilidade de recuperação daqueles espaços decisionais que a organização estatal, sempre invasiva e juridificada, passo a passo subtraiu (SPENGLER, 2017, p.11).

Quanto à Mediação Comunitária, esta é instrumento de política pública eficaz de tratamento de conflitos, que tem por finalidade possibilitar o acesso à justiça a toda e qualquer pessoa, a promoção da harmonização dos interesses e inclusão social, e ainda o empoderamento e a emancipação das partes e da comunidade no tratamento das suas demandas, com a prevenção do surgimento de novos conflitos (WÜRT, 2014, p.12).

Certo é que, com a crise do judiciário brasileiro, revela-se imprescindível a construção de um novo paradigma de transformação da cultura litigiosa em pacificadora. Para Antonio Carlos Wolkmer, há a necessidade da construção de novas práticas cotidianas, através do pluralismo, que "reconhece que a vida humana é constituída por seres, objetos, valores, verdades, interesses e aspirações marcadas pela essência da diversidade, fragmentação, circunstancialidade, temporalidade, fluidez e conflituosidade" (WOLKMER, 2015, p. 186).

Ainda, os autores Antonio Carlos Wolkmer e Maria de Fátima S. Wolkmer (2021, p.132) ao referirem sobre o Pluralismo Jurídico, apontam que:

Um pluralismo jurídico de tipo comunitário e participativo é aquele que se pode repensar, não apenas em um nível geral, a questão da administração e do acesso à justiça, mas aproximar, em um nível específico, as experiências contemporâneas de mecanismos alternativos de resolução de conflitos.

Percebe-se que, ao permitir que os integrantes de determinada comunidade compreendam melhor o seu contexto e que possam auxiliar na efetivação dos seus direitos, estar-se-á possibilitando a interculturalidade, a descolonização e a emancipação desses indivíduos. A importância do papel da Mediação Comunitária, é mencionado por Carolina Würt (2014, p.12):

Trata-se de uma proposta inovadora, na medida em que pretende devolver aos membros das comunidades mais carentes o sentimento de pertencimento e de inclusão por meio da instituição de práticas consensuais-dialógicas que visam resgatar os laços de amizade e fraternidade enfraquecidos, ou seja, ambiciona-se 
pensar a jurisdição em um sentido mais amplo.

Os autores José Laurindo De Souza Netto, Jenyfer Michele Pinheiro Leal e Adriane Garcel (2020, p.8), referem:

Em síntese, mediação comunitária é aquela desenvolvida dentro das comunidades com o objetivo de resolver os conflitos cotidianos, por intermédio do diálogo, que pode ser utilizada em vários segmentos da comunidade, v.g., nas escolas, nas instituições religiosas, na segurança pública, em condomínios, no ambiente de trabalho e dentre vários outros setores.

Ainda, os autores citados mencionam a importância da comunicação para a solução desses conflitos bem como para o restabelecimento dos vínculos entre os litigantes.

\begin{abstract}
Diante do contexto de violência que a sociedade vivencia atualmente é de extrema importância buscar por caminhos que ajudem a tratar os conflitos oriundos do convívio social. A comunicação pode ser uma delas. O restabelecimento da comunicação entre as pessoas que enfrentam algum conflito é capaz de auxiliar na resolução do litígio, isso porque as partes passam a ter oportunidade de falar e ouvir o outro, o que faz com que tenham conhecimento e compreensão das razões que levaram o indivíduo a praticar determinada conduta e passam a buscar medidas que resolvam o problema. (NETTO; LEAL; GARCEL, 2020, p. 2-3)
\end{abstract}

Quando cita-se a Mediação Comunitária, por óbvio, está a se falar sobre a coletividade, ações que abrangem as atuações relacionadas com a comunidade, estas que, quase sempre, são questões de âmbito público.

Especificamente sobre a Mediação Comunitária, Elaine Cler Alexandre dos Santos (2018, p.66) refere que:

Os conflitos comunitários podem e devem ser solucionados pela mediação, ou seja, pela intercessão de pessoas imparciais voltadas a ajudar sua comunidade, em busca da promoção do desenvolvimento local, promovendo, com e pela população, seu funcionamento, em termos de bem-estar social, econômico e cultural, criando condições, estruturas e relações propícias para isso, com trabalhadores profissionais ativos em uma ampla variedade de campos, informação de grupo, renovação urbana, educação, centros de crescimento, minorias, estruturas sociais a nível local, distrital e regional, clube-casa e centro social de bairro, entre outras.

Conceituando a Mediação Comunitária, Gláucia Falsarella Foley ([s.d.], p.5) esclarece que:

A mediação comunitária tem por objetivo promover a democratização do acesso à 
justiça, restituindo ao cidadão e à comunidade a capacidade de gerir seus próprios conflitos de maneira participativa, autônoma e emancipatória. Nesse sentido, para que seja efetivamente comunitária e não se limite a operar como meio de resolução de conflitos, a prática da mediação deve estar articulada à educação para os direitos e à animação de redes sociais.

Com isso podemos intuir que a Mediação Comunitária, é uma forma de democratização da justiça, eis que permite a resolução de conflitos dentro da própria comunidade. Esse é o entendimento de Marina Pereira Manoel Gomes([s.d.], p.19):

\begin{abstract}
Esse mecanismo de solução de disputas, tendo em vista que é composto, na maioria dos casos, de moradores locais investidos no papel de mediadores, dissemina a justiça de forma democrática e direta em relação ao caso concreto, ao passo em que orienta a sociedade para a pacificação.
\end{abstract}

Assim, tem-se que a Mediação também oportuniza a inclusão social dos indivíduos quando procura conscientizá-los sobre a importância da participação ativa na concretização dos direitos e deveres. Portanto, a ocorrência do conflito deve ser vista como a chance de transformação com a ajuda de cada indivíduo (AZEVEDO, 2011, p.3).

No entendimento de Kazuo Watanabe, há a necessidade de conscientizar as partes envolvidas de que deverão encontrar a solução para o litígio.

Se as partes não forem pacificadas, se não se convencerem de que elas devem
encontrar uma solução de convivência, isto é, se a técnica não for a da pacificação
dos conflitantes, e sim a da solução dos conflitos, as mesmas partes retornarão ao
tribunal outras vezes. Então, existe diferença no tratamento de conflitos entre duas
pessoas em contato permanente e entre aquelas que não se conhecem
(WATANABE, 2003, p.46).

Por isso, é fundamental o desenvolvimento das técnicas de Mediação Comunitária a fim de proporcionar o ataque ao real problema do conflito, sem que as partes envolvidas sejam atacadas. O que realmente se deseja é a transformação não só das partes litigantes, mas da comunidade em geral, buscando a paz social. Nesse sentido, vemos que:

A emergência de novas práticas sociais na comunidade promove profundas transformações nas relações individuais, sociais e institucionais. A prática da mediação, como um dos eixos da mediação comunitária, é capaz de converter o conflito em oportunidade para o desenvolvimento de confiança e reconhecimento das identidades; senso de pertencimento e cooperação; celebração de novos pactos e restauração do tecido social. E é exatamente esse processo de transformação que promove coesão social, autonomia e emancipação, tal qual ansiado pela mediação comunitária (FOLEY, [s.d], p.17). 
Assim, é possível visualizar como objetivos essenciais da Mediação, a solução dos conflitos, o cuidado à má administração de conflitos e a inclusão social. Facilitar o diálogo entre as pessoas, na busca da solução para seus problemas, é uma forma de resgate da cidadania através da educação social.

Não há mais espaço para uma justiça centralizadora que não atende as demandas da sociedade, que causa injustiças e desigualdades. Nesse sentido, os autores Antonio Carlos Wolkmer e Maria de Fátima S. Wolkmer (2021, p.130) referem:

\begin{abstract}
Assim o paradigma jurídico monista e estatista não encontra mais sintonia na realidade social e nas suas instituições tradicionais de produção e de resolução de conflitos. O que se exige é uma transformação democrática e participativa da justiça. A administração da justiça atravessa, como um todo, a problematização do contexto de crise, gerando a imperiosidade de mudar os procedimentos jurisdicionais do Estado moderno e o profundo questionamento de seus implantes históricos na evolução colonizadora dos países da América Latina.
\end{abstract}

Posto isso, percebe-se que o pluralismo jurídico e os meios alternativos de resolução de conflitos são a solução para a concretização dos direitos, sendo que a Mediação Comunitária se consolida como um método real de efetivação dos direitos.

\title{
3. ANÁLISE PRINCIPIOLÓGICA DA MEDIAÇÃo COMUNITÁRIA
}

A Mediação possui alguns princípios gerais que devem ser acatados, já que referido procedimento é um meio alternativo de pacificação. A Lei no. 13.140/15 (Lei de Mediação), em seu artigo $2^{\text {ol }}$ dispõe sobre os princípios que norteiam a Mediação, sendo eles o da imparcialidade do mediador; isonomia entre as partes; oralidade; informalidade; autonomia da vontade das partes; busca do consenso; confidencialidade e boa-fé.

Há um certo consenso entre os estudiosos quanto aos princípios da Mediação de conflitos, que apontam a liberdade das partes, não competitividade, poder de decisão das partes, participação de terceiro imparcial, competência do mediador, informalidade do

\footnotetext{
${ }^{1}$ Art. $2^{\circ}$ A mediação será orientada pelos seguintes princípios:

I - imparcialidade do mediador;

II - isonomia entre as partes;

III - oralidade;

IV - informalidade;

V - autonomia da vontade das partes;

VI - busca do consenso;

VII - confidencialidade;

VIII - boa-fé.
} 
processo, confidencialidade e sigilo no processo como regras a serem seguidas (SALES; CHAVES, 2014, p.263).

O presente artigo tem como pretensão realizar uma abordagem quanto aos princípios gerais norteadores da Mediação Comunitária. Para isso, serão analisados os princípios da liberdade das partes, da decisão das partes, da não competitividade, da competência do mediador e da participação de terceiro imparcial, e da confidencialidade e informalidade do processo.

Para as partes envolvidas no litígio "compreender a mediação enquanto um procedimento viável e capaz de solucionar conflitos significa, antes de tudo, conhecer os seus princípios basilares e de que maneira eles interagem entre si” (MIRANDA NETTO et al.; 2014, p.108).

Assim, o primeiro princípio a ser analisado é o da liberdade das partes, ou seja, estas deverão escolher de forma livre o caminho que querem seguir para resolver o seu conflito. Para isso, devem ter a liberdade para escolher o seu mediador, e se acharem conveniente poderão pôr fim ao procedimento. Nesse contexto, Elaine Cler Alexandre Dos Santos (2018, p.75):

\footnotetext{
Uma vez colocada em prática, a mediação pode trazer uma contribuição efetiva às próprias coletividades, possibilitando maior autonomia por parte dos sujeitos envolvidos, que se sentem protagonistas e conscientes das possibilidades de resolverem seus próprios conflitos, podendo se constituir em atitude e comportamento cotidiano na comunidade da qual fazem parte, portanto na definição de uma nova cultura de justiça social.
}

Essa autonomia que é dada as partes permite que se sintam responsáveis pela paz que procuram, fazendo com que haja uma mudança de comportamento, que mudem suas atitudes frente a outros problemas a serem enfrentados.

Como bem assevera Fernando Gama de Miranda Netto et al. (2014, p.109):

\footnotetext{
A autonomia da vontade, principalmente enquanto autodeterminação, é fundamental não só para garantir a liberdade das pessoas, como também para assegurar a eficácia e funcionamento da mediação. Respeitar esse princípio é, acima de tudo, dar às partes o total esclarecimento de seu protagonismo no procedimento, para que posteriormente, com a emergência de um possível acordo, possam redigi-lo de forma tão natural que efetivamente o cumpram.
}

Às partes deve ser proposta a Mediação como opção para resolver o conflito. No 
entanto, a recusa em mediar não dever ter influência no resultado final do processo judicial.

No que tange o princípio do poder de decisão das partes, salienta-se que a solução para o litígio é das partes, já que estas é que deverão encontrar uma solução pacífica para o seu conflito. Em algumas situações esse poder de decisão não é absoluto. Os autores Aidi Lucena Carvalho, Bertoldo Klinger Rego Barros Neto e Filipe Franco Santos (2012, p.01), explicam que "o mediador pode (e deve) impedir que sejam celebrados acordos cujo o objeto seja ilegal ou que tragam desvantagem para uma das partes".

É importante observar, a propósito, que a autonomia da vontade não é soberana no
Direito contemporâneo. No procedimento da mediação, ela é limitada em muitos
aspectos. Para uma exposição didática, é possível classificar tais limitações em três
diferentes dimensões: interpessoais, internas e externas. As limitações interpessoais
dizem respeito ao fato das proposições de acordo e alterações procedimentais
sugeridas por uma das partes, no âmbito de sua respectiva autonomia, serem
limitadas pela autonomia da parte adversária. As limitações internas, por sua vez,
são constituídas por outros dispositivos dos próprios marcos normativos da
mediação (a Resolução no 125/2010 do CNJ, a Lei da Mediação e o Código de
Processo Civil) (MEIRA; RODRIGUES, 2017, p.106-107).

Abordando o princípio da não competitividade, cabe mencionar que tem-se a ideia, no mundo jurídico, que há sempre um perdedor e um ganhador. Porém na Mediação essa concepção não existe e não deve existir. Isso porque a Mediação é baseada no respeito entre as partes e no diálogo, deixando de visualizar o litígio como uma disputa onde deve haver um perdedor e um ganhador, mas sim como um método de pacificação, onde ambas as partes podem sair ganhando.

Quando se fala do princípio da competência do mediador e da participação de terceiro imparcial, há algumas situações que devem ser observadas, como qualidade de percepção do mediador, conhecimento da realidade da comunidade onde realizará a mediação, além claro da atuação com ética e imparcialidade. Tem-se que a imparcialidade do mediador é supervalorizada por ocasião da realização da mediação.

$\mathrm{O}$ artigo $5^{\mathbf{0}^{2}}$ da Lei de Mediação, determina que sejam aplicadas ao mediador as mesmas presunções legais de impedimento e suspeição que são aplicadas ao juiz. Além disso, a lei traz outras determinações ao mediador, como não atuar como testemunha em processos judiciais pertinentes ao conflito em que tenha atuado como mediador, não assessorar,

\footnotetext{
${ }^{2}$ Art. $5^{\circ}$ Aplicam-se ao mediador as mesmas hipóteses legais de impedimento e suspeição do juiz. Parágrafo único. A pessoa designada para atuar como mediador tem o dever de revelar às partes, antes da aceitação da função, qualquer fato ou circunstância que possa suscitar dúvida justificada em relação à sua imparcialidade para mediar o conflito, oportunidade em que poderá ser recusado por qualquer delas.
} 
representar ou patrocinar qualquer das partes. Em geral, nem o que for dito na Mediação nem os documentos apresentados nesse contexto poderão ser usados como provas num processo judicial sobre o mesmo litígio.

Esclarece Danilo Christiano Antunes Meira e Horácio Wanderlei Rodrigues (2017, p.113):

\begin{abstract}
São deveres claros e objetivos, mas alguns dificilmente podem ser aplicados voluntariamente pelo mediador. O primeiro, o dever de agir com ausência de favoritismo e preferência, significa que o mediador não poderá conduzir o procedimento de modo a privilegiar uma das partes. $\mathrm{O}$ dever de recusar favores ou presentes é um complemento desse primeiro dever, pois a aceitação criaria a presunção de que o mediador se torna moralmente obrigado a retribuir à parte doadora. O segundo, o dever de agir com ausência de preconceito, pode ser compreendido como o dever do mediador de suspender juízos morais de qualquer natureza que eventualmente possa ter em relação a qualquer das partes com potencial de prejudicá-la. Os deveres de afastar valores e conceitos pessoais e de compreender a realidade dos envolvidos são complementos desse segundo dever.
\end{abstract}

Deve ficar claro, que o mediador deve manter uma posição neutra, sem tomar partido no litígio. Também não pode aconselhar as partes, estas poderão procurar aconselhamento jurídico durante o processo de mediação se julgarem necessário. Ainda, de forma alguma poderá o mediador agir de maneira que satisfaça interesses pessoais quando da realização da Mediação.

A comunicação do mediador com as partes é essencial. Por isso, a escolha de um mediador que esteja inserido na rede social comunitária facilitará a realização da mediação, pois se vislumbrará o fator da identidade entre o mediador e as partes.

Outro princípio a ser abordado, é o da confidencialidade e informalidade do processo. No processo judicial, com algumas exceções, há a publicidade dos atos, ao contrário do que se dá na Mediação.

No que se refere a confidencialidade, o artigo $30^{3}$ da Lei de Mediação deixa claro

\footnotetext{
${ }^{3}$ Art. 30. Toda e qualquer informação relativa ao procedimento de mediação será confidencial em relação a terceiros, não podendo ser revelada sequer em processo arbitral ou judicial salvo se as partes expressamente decidirem de forma diversa ou quando sua divulgação for exigida por lei ou necessária para cumprimento de acordo obtido pela mediação.

$\S 1^{\circ} \mathrm{O}$ dever de confidencialidade aplica-se ao mediador, às partes, a seus prepostos, advogados, assessores técnicos e a outras pessoas de sua confiança que tenham, direta ou indiretamente, participado do procedimento de mediação, alcançando:

I - declaração, opinião, sugestão, promessa ou proposta formulada por uma parte à outra na busca de entendimento para o conflito;

II - reconhecimento de fato por qualquer das partes no curso do procedimento de mediação;

III - manifestação de aceitação de proposta de acordo apresentada pelo mediador;
} 
que, tanto as partes quanto o conflito devem ser mantidos em sigilo, evitando com isso algum tipo de constrangimento para as partes.

Esclarece Rodrigo Nunes Kops e Ana Paula Zitzke (2015, p.13) que "cada processo de mediação é único e possui peculiaridades. Assim, o trabalho do mediador requer neutralidade, paciência, confidencialidade e facilidade de comunicação, dentre outras habilidades".

Ao referir-se sobre a função do mediador, Luiz Alberto Warat (2004, p.26) ressalta que:

O mediador deve entender a diferença entre intervir no conflito e nos sentimentos das partes. O mediador deve ajudar as partes, fazer com que olhem a si mesmas e não ao conflito, como se ele fosse alguma coisa absolutamente exterior a elas mesmas (WARAT, 2004, p. 26).

Assim, as partes envolvidas no litígio terão confiança no mediador, revelando todos os fatos, sem o medo de que, o que foi revelado, seja levado a conhecimento de terceiros.

O princípio da informalidade não deixa de ser importante, ainda que, aparentemente, ocupe uma posição inferior aos demais princípios. Levando em consideração que a Mediação foi criada para que houvesse um restabelecimento do diálogo entre os litigantes, fácil é a compreensão da necessidade de que o procedimento seja de maior liberdade, com o afastamento de regras não obrigatórias.

Nesse contexto, Meira e Rodrigues (2017, p.116), apontam que:

No contexto da mediação, obviamente, essa carga semântica precisa ser deflacionada. Não é possível entender a informalidade aqui como ausência de regras. A informalidade é limitada explicitamente por todas as normas cuja observância foi instituída como condição de validade da mediação. Constituem exemplos dessas limitações a norma que obriga a lavratura de termo final, a norma que torna obrigatória a assistência de advogado ou defensor público na mediação judicial, a norma que exige a licitude do acordo, a norma que estabelece o dever do mediador de revelar fatos que possam suscitar dúvidas quanto a sua imparcialidade, etc.

IV - documento preparado unicamente para os fins do procedimento de mediação.

$\S 2^{\circ}$ A prova apresentada em desacordo com o disposto neste artigo não será admitida em processo arbitral ou judicial.

$\S 3^{\circ}$ Não está abrigada pela regra de confidencialidade a informação relativa à ocorrência de crime de ação pública.

$\S 4^{\circ}$ A regra da confidencialidade não afasta o dever de as pessoas discriminadas no caput prestarem informações à administração tributária após o termo final da mediação, aplicando-se aos seus servidores a obrigação de manterem sigilo das informações compartilhadas nos termos do art. 198 da Lei $\mathrm{n}^{\circ}$ 5.172, de 25 de outubro de 1966 - Código Tributário Nacional.

Art. 31. Será confidencial a informação prestada por uma parte em sessão privada, não podendo o mediador revelá-la às demais, exceto se expressamente autorizado. 
Cabe mencionar ainda, o importância do papel da comunidade na solução dos litígios, resgatando seus valores intrínsecos. É nesse sentido que José Laurindo De Souza Netto, Jenyfer Michele Pinheiro Leal e Adriane Garcel (2020, p.12), aludem:

\begin{abstract}
À vista disso é que surge a necessidade do auxílio da comunidade em dirimir os desentendimentos advindos do convívio social e melhorar a convivência através da mediação comunitária. Máxime sob a ótica de que o Judiciário está sobrecarregado de processos, assim, tem-se que o auxílio da comunidade é de grande importância, não só para evitar processos desnecessários, mas também para resgatar os valores sociais introitos no convívio em comunidade. Sobretudo, propiciando o acesso à justiça as pessoas mais carentes naquele meio social, pois, como é cedido, o acesso à justiça não é somente ter acesso ao Judiciário, mas sim obter uma resposta justa e razoável de modo que a decisão seja imparcial e efetiva as partes e, isso, pode, sim, ser conquistado através de uma boa mediação
\end{abstract}

Posto isso, buscou-se demonstrar que a Mediação Comunitária é uma importante ferramenta para o concreto acesso à justiça, pois, embasada nos seus princípios propõe solucionar os conflitos comunitários, assegurando com isso o restabelecimento das relações entre as partes litigantes bem como a busca pela paz social.

A utilização da Mediação Comunitária ao mesmo tempo que permite o empoderamento do cidadão pertencente a determinada comunidade, traz a este a responsabilidade pela solução do conflito.

\title{
4. CONSIDERAÇÕES FINAIS
}

Em razão do abalo na credibilidade do Poder Judiciário, devido à crise que vem passando, ocasionada pela enorme demanda judicial existente, bem como pela excessiva demora nos julgamentos das lides, buscaram-se outras alternativas para a solução dos conflitos.

Dentre essas alternativas está a Mediação Comunitária que cada vez mais ganha força, pois é vista como uma forma democrática para a resolução do conflito e, ainda, de pacificação social. Muito antes de ser uma alternativa para enfrentamento da crise do Judiciário, a mediação mostra que o modelo de resolução de litígios padrão não é o adequado para resolver os problemas complexos das relações sociais.

A prática desse tipo de mediação busca criar um canal de comunicação entre os integrantes da comunidade, dando a oportunidade de resolverem seus problemas, com o 
auxílio de um mediador, que não necessariamente precisa ser um membro da comunidade.

É consenso que a Mediação Comunitária estimula o diálogo entre as partes envolvidas no conflito, e mais, busca reestabelecer os laços entre os mesmos, sendo essa uma das principais finalidades da mediação. A chance de saírem satisfeitos com a solução que ambos criaram é muito maior do que aquela determinada pelo Poder Judiciário.

Tal método de solução consensual de conflitos serve como mola propulsora para que os integrantes da comunidade percebam que são detentoras de direitos e deveres e que dessa forma a pacificação social está em suas mãos.

E analisando os princípios da liberdade das partes, da decisão das partes, da não competitividade, da competência do mediador e da participação de terceiro imparcial, e da confidencialidade e informalidade do processo, percebe-se que todos são importantes e fundamentais para que a mediação seja efetiva, atingindo dessa forma sua finalidade.

Conclui-se assim, que a Mediação Comunitária é uma oportunidade de regaste dos valores sociais, representando uma alternativa para a redução da competitividade individual, em que há um ganhador e um perdedor, servindo de base e ferramenta para uma solução mais eficaz e de pacificação social.

Deve-se ponderar ainda, a importância do Pluralismo Jurídico na transformação do direito e na construção de novas formas de solução dos conflitos, não significando com isso, a negação do papel do Estado como órgão responsável na decisão das demandas, mas a possibilidade de se usufruir de outras alternativas efetivas de pacificação social.

\section{REFERÊNCIAS}

AZEVEDO, L. M. X. de. A mediação comunitária como mecanismo extrajudicial de solução de conflitos: a contribuição do núcleo de justiça comunitária do ministério público para o protagonismo da população do Pirambu durante o ano de 2010. Revista Acadêmica da ESMPCE, v. 2, p. 1, 2011. Disponível em: <http://tmp.mpce.mp.br/esmp/publicacoes/edi002_2011/artigos/02Mediacao.Comunitaria.como.Mecanismo.Extrajudicial.pdf>. Acesso em: 04 abr. 2021.

BRASIL. Lei $\mathbf{n}^{\circ}$ 13.140, de 26 de junho de 2015. Dispõe sobre a mediação entre particulares como meio de solução de controvérsias e sobre a autocomposição de conflitos no âmbito da administração pública; altera a Lei $\mathrm{n}^{\circ} 9.469$, de 10 de julho de 1997 , e o Decreto $\mathrm{n}^{\circ} 70.235$, de 6 de março de 1972; e revoga o $§ 2^{\circ}$ do art. $6^{\circ}$ da Lei $n^{\circ} 9.469$, de 10 de julho de 1997. Brasília, 26 de junho de 2015. Disponível em: <http://www.planalto.gov.br/ccivil_03/_ato2015-2018/2015/lei/113140.htm>. Acesso em: 04 
abr. 2021.

CAPPELLETTI, M.; GARTH, B. Acesso à justiça. Porto Alegre: Sergio Antonio Fabris, 1988.

CARVALHO, A. L.; BARROS NETO, B. K. R.; SANTOS, F. F. S. A mediação comunitária como instrumento de acesso à justiça e efetivação da cidadania: uma nova perspectiva do conceito de justiça e de conflito. 2012. Disponível em: <https://www.webartigos.com/artigos/a-mediacaocomunitaria-como-instrumento-de-acesso-a-justica-e-efetivacao-da-cidadania-uma-novaperspectiva-do-conceito-de-justica-e-de-conflito/87851>. Acesso em 04 abr. 2021.

FOLEY, G. F. Mediação Comunitária para a Emancipação Social. In: ENAM, Escola Nacional de Mediação e Conciliação. Fundamentos da Mediação Comunitária. [s.d]. Disponível em:

<http://institutoelo.org.br/site/files/arquivos/a4b78d82ae0081b9626d1e06d9f98ce8.pdf>. Acesso em: 04 abr. 2021.

GOMES, M. P. M. Mediação comunitária e o princípio da solidariedade: o acesso à justiça pela disseminação da cultura de paz nas comunidades. [s.d.]. Disponível em: <http://www.publicadireito.com.br/artigos/?cod=e465ae46b07058f4>. Acesso em: 04 abr. 2021.

KOPS, R. N.; ZITZKE, A. P. A mediação comunitária como política pública transformadora da sociedade. In: XII SEMINÁRIO INTERNACIONAL DE DEMANDAS SOCIAIS E POLITICAS PÚBLICAS NA SOCIEDADE CONTEMPORANEA, 2015. Disponível em: <https://online.unisc.br/acadnet/anais/index.php/sidspp/article/view/13197>. Acesso em: 04 abr. 2021.

MEIRA, D. C. A.; RODRIGUES, H. W. O conteúdo normativo dos princípios orientadores da mediação. R Jur. UNI7, Fortaleza, v. 14, n. 2, p.101-123, jul./dez. 2017. Disponível em: <https://www.uni7.edu.br/periodicos/index.php/revistajuridica/issue/view/26/ano2017-2>. Acesso em 04 abr. 2021.

MIRANDA NETTO, F. G. de et al. Protagonismo das partes e os princípios da neutralidade e da imparcialidade na mediação civil. In: MIRANDA NETTO, F. G. de (org.). Mediação nas comunidades e nas instituições. Niterói: PPGSD - Programa de Pós-Graduação em Sociologia e Direito, 2014. Disponível em: <http://www.professores.uff.br/fernandogama/wpcontent/uploads/sites/15/2017/07/livromediacao.pdf>. Avesso em: 04 abr. 2021.

NASCIMENTO JUNIOR, V. de F. A evolução dos métodos alternativos de resolução de conflitos em ambiente virtual: on-line dispute resolution. Revista Eletrônica da Faculdade de Direito de Franca, v.12, n.1, p.265-282, jul. 2017. Disponível em: $<$ https://www.revista.direitofranca.br/index.php/refdf/article/view/439/pdf > Acesso em: 04 abr. 2021.

NETTO, J. L. S.; LEAL, J. M. P.; GARCEL, A. MEDIAÇÃO COMUNITÁRIA: UM MECANISMO PARA A EMANCIPAÇÃO DO SER HUMANO. Relações Internacionais no Mundo Atual, [S.1.], v. 3, n. 28, p. 39 - 56, nov. 2020. ISSN 2316-2880. Disponível em: 
<http://revista.unicuritiba.edu.br/index.php/RIMA/article/view/4542/371372716>. Acesso em: 11 abr. 2021.

PANTOJA, F. M.; ALMEIDA, R. A. de. Os métodos "alternativos de resolução de conflitos" (ADRS). In: ALMEIDA, T.; PELAJO, S.; JONATHAN, E. (Coords.). Mediação de conflitos para iniciantes, praticantes e docentes. Salvador: Juspodivm, 2016.

RANGEL, T. L. V. A comunidade como locus de promoção das práticas de mediação: o empoderamento do indivíduo no tratamento de conflitos. In: MIRANDA NETTO, F. G. de (org.). Mediação nas comunidades e nas instituições. Niterói: PPGSD - Programa de PósGraduação em Sociologia e Direito, 2014. Disponível em:

$<$ http://www.professores.uff.br/fernandogama/wpcontent/uploads/sites/15/2017/07/livromediacao.pdf>. Avesso em: 04 abr. 2021.

RUIZ, I. A. A mediação no direito de família e o acesso à justiça. In: SOUZA, L. M. de (Coord.). Mediação de conflitos: novo paradigma de acesso à justiça. 2.ed. Santa Cruz do Sul: Essere Nel Mondo, 2015.

SALES, L. M. de M.; CHAVES, E. C. C. Mediação e Conciliação Judicial: A Importância da Capacitação e de seus Desafio. Seqüiência, Florianópolis, n. 69, p. 255-280, dez., 2014. Disponível em: <http://www.scielo.br/pdf/seq/n69/11.pdf〉. Acesso em: 04 abr. 2021.

SANTOS, E. C. A. dos. Direitos humanos e efetividade no processo participativo de desenvolvimento local: Mediando relações comunitárias. In: XXVII ENCONTRO NACIONAL DO CONPEDI. Salvador: CONPEDI, 2018.

SILVA, J. B.; THIBAU, T. C. S. B.; MACHADO, E. D. (coords.). Direito e política: da vulnerabilidade à sustentabilidade. In: CONPEDI - CONSELHO NACIONAL DE PESQUISA E PÓS-GRADUAÇÃO EM DIREITO, Universidade Federal de Minas Gerais (UFMG), Belo Horizonte, nov., 2015. Disponível em: <https://www.conpedi.org.br/wpcontent/uploads/2015/10/programacao_conpedi_bh_web2.pdf >. Acesso em: 04 abr. 2021.

SPENGLER, F. M. Mediação: técnicas e estágios. Santa Cruz do Sul: Essere nel Mondo, 2017.

WARAT, Luiz Alberto. Surfando na pororoca: ofício do mediador. Florianópolis: Fundação Boiteux, 2004.

WATANABE, K. Modalidade de mediação. In: DELGADO, J. Et al. Mediação: um projeto inovador. Brasília: Centro de Estudos Judiciários, CJF, 2003.

WOLKMER, Antonio Carlos. Pluralismo jurídico: fundamentos de uma nova cultura no direito. 4.ed. São Paulo: Saraiva, 2015.

WOLKMER, Antonio Carlos; WOLKMER, Maria de Fatima S.. Horizontes Contemporâneos do Direito na América Latina. Criciúma: UNESC, 2021, p. 130-136.

WÜRT, Carolina Wurt. Mediação comunitária e acesso à justiça: as duas faces da 
metamorfose social. Santa Cruz do Sul: Essere Nel Mondo, 2014.

YAGODNIK, E. B.; MARQUES, G. P. Y. Breves considerações acerca da mediação e de sua regulamentação legislativa no Brasil. In: MIRANDA NETTO, F. G. de (org.). Mediação nas comunidades e nas instituições. Niterói: PPGSD - Programa de Pós-Graduação em Sociologia e Direito, 2014. Disponível em: <http://www.professores.uff.br/fernandogama/wpcontent/uploads/sites/15/2017/07/livromediacao.pdf>. Avesso em: 04 abr. 2021.

ZANFERDINI, F. de A. M. Desjudicializar conflitos: uma necessária releitura do acesso à justiça. Novos Estudos Jurídicos, v.17, n.2, p.237-253, 2012. Disponível em:

<http://siaiap32.univali.br/seer/index.php/nej/article/view/3970>. Acesso em: 04 abr. 2021. 